\title{
A Reflection on the Transformation of the Economic Development Model in China
}

\author{
Xiaoming Qiao \\ Journal Editorial Department, Yunnan Normal University, Kunming City, \\ Yunnan Province, 650092, China
}

\begin{abstract}
Since reform and opening up, China's economy has made remarkable achievements. However, high investment, high consumption, high pollution and other shortcomings of the traditional development model have not been fundamentally changed and China's economy have not grown its way out of extensive growth. This paper analyzed the evolution of China's macro-economic development model since the reform and opening up from the perspective of growth momentum, growth structure, growth efficiency and growth sustainability. Then, the paper demonstrated the basic transformation path from the traditional economic development model to the new economic development model.

Keywords: Economic development model; Economic growth structure; Extensive economic growth; Technological innovation
\end{abstract}

\section{Introduction}

The economic development of the world has demonstrated that the traditional economic growth model has not only made remarkable achievements in increasing the material wealth of the society, but also caused a variety of social and environmental problems. How to realize the transformation from the traditional extensive growth model to the new intensive development model is a common problem faced by all countries in the world. Since its reform and opening up, China has been committed to change the traditional economic growth and development model, but the effect is not satisfactory[1]. The extensive growth with high input, high consumption, high pollution and low efficiency has 
not been fundamentally changed. The transformation of China's economic growth and development model has a long way to go.

\section{The Structural Contradiction of the Economic Growth is Prominent}

\subsection{The contribution rate of the secondary industry to the economic growth is high}

There is a necessary relation between the economic development and the evolution of the industrial structure. The history of the economic development is the ever-changing history of the industrial structure and the industrial structure change promotes the economic development level. Petty-Clark Theorem indicates that with the development of the economy, factors of production are tended to transfer to the secondary and tertiary industries with increasing factor rewards. The proportion of the primary industry output value will continue to decline in the total output value and the proportion of the tertiary industry will eventually exceed the secondary industry[2]. The over-reliance of the economic development on the secondary industry has not been transformed fundamentally. Since 2002, the proportion of the secondary industry output value increases significantly and the proportion of the tertiary industry output value continues to decline, which indicates that with China's rapid economic growth, the industrial structural contradiction becomes increasingly prominent. This will hinder China's stable economic development in a long term.

\subsection{The role of consumption in stimulating economic growth is gradually declining}

The modern economic theory believes that in the market economy, the total social demand, including domestic demand and foreign demand, is the driving force to stimulate economic growth. The domestic consumption demand is the final demand, which is the fundamental driving force to promote economic growth. The rise of the investment demand must be based on the increase of consumer demand, so as to play its role in promoting economic growth. According to relevant data in the database, the average investment rate in countries of the world dropped from $25.6 \%$ to $19.9 \%$ from 1970 to 2002 . From 2002 to 2004, the investment rate of developed countries and most developing countries was generally between $20 \%$ and $30 \%$. However, China's average investment rate was as high as $37.3 \%$ from 1978 to 2006. Whether compared with developed countries or developing countries, China's investment rate is significantly higher and economic growth excessively depends on investment growth. 


\subsection{Government investment plays a special role in the economic growth}

From the perspective of investors, the social investment can be divided into government investment and private investment. Government investment is nonprofit and its efficiency is generally lower than private investment. At the same time, too much government investment will have a crowding-out effect on private investment, which hinders economic growth. This means that in the market economy, government investment should be more constrained in investment scale and investment direction[3]. The role of government investment in economic operation is mainly to promote the development of public utilities and create basic conditions for private investment, so as to ensure the sustainable economic growth. Judging from the inherent requirement of the market economy to the government function, the special role of government investment in the economic growth will constrain the transformation of China's economic development model.

\section{The Efficiency Level of the Economic Growth is Low}

\subsection{The contribution of total factor productivity to economic growth decreases significantly}

Essentially, economic growth is the result of the increase of various factors input and improvement of the efficiency in the coordination of different factors. Economic growth which mainly depends on the increasing input of capital, labor and other production factors is an extensive growth; economic growth which relies on technological progress, investment in human capital and institutional innovation, and which improves the efficiency of coordination between factors is intensive growth. Clearly, economic growth must be driven by intensive growth. Since 1992, the contribution of capital investment gradually increased, while the contribution of TFP is declining year by year. This shows that China's economic growth mainly depends on production factors, especially the increase in capital investment. This is still a typical extensive economic growth model[4].

\subsection{The effect of the fixed-asset investment is poor}

The effect coefficient of the fixed-asset investment in China is low for a long time. From 1980 to 2005 , the average investment effect coefficient is 0.42 ; the peak value is 0.71 and the minimum value is 0.12 , which shows a great fluctuation. At the same time, since 1998, the investment effect coefficient is basically in the lowest level in history. The fluctuation of the investment effect coefficient reflects that there is a lot of waste in the fixed- asset investment and it does not play its role in promoting economic growth. It also shows that with the growth of the fixed-asset investment, the marginal investment efficiency is declining. The potential that China depends on investment to stimulate economic growth is gradually weakened. 
3.3 Economic growth has paid a heavy price for the continuous deterioration of the ecological environment

The ecological environment is the basis for the survival and development of human society. Resource abuse, environmental pollution, grassland degradation, species extinction and other ecological and environmental problems that appear with the economic growth not only constraint the economic growth, but also constitutes a serious threat to human's development. To achieve the coordinated development between the economy, society and ecological environment is a consensus in the world[5].

With the rapid economic growth, the amount of industrial waste gas, waste water and emission of other pollutants is increasing. One third of the land in China has been attacked by acid rain; a quarter of the residents do not have clear drinking water; one third of the urban population have to breathe polluted air. With the further expansion of economic scale, the pressure of resources, ecology and environment that China face is bound to be higher, which will further restrain the economic development.

\section{The Technical Support for the Economic Growth is Weak}

\subsection{There is a significant gap in technological level between China and the developed countries}

Due to the influence of various factors, there is no standardized and accurate criteria in the academic community to measure the gap of technical level between different countries. However, we can still draw on from the relevant literature that there is a significant gap in technological level between China and the developed countries[6]. In general, at the beginning of the reform and opening-up, the gap of the technological level between China and developed countries is about 20 years and this gap is still not significantly narrowed now.

4.2 Technological innovative ability restricts the economic growth seriously

The gap of the technological level between China and the developed countries stems from China's weak capacity of independent innovation and China ranks from twenty-fifth to thirtieth in science and technology competitiveness internationally[7]. The first prize of State Technological Invention Award has been left vacant for six consecutive years, which reflects that China's scientific and technological achievements lack significant original innovation.

\section{Conclusion and Suggestions}

5.1 To eliminate the inherent impulse of government investment expansion and prevent low-level redundant construction 
Economic growth is too dependent on the increase of investment, especially the increase of government investment. It is a stubborn shortcoming in the economic operation and the direct reason why China's economy still does not grow its way out of the extensive growth. In order to give full play to the role of domestic consumption in promoting economic development, and promote the change from the investment-driven development model to the consumption-driven development model and from the export-oriented development model to the domestic demand-oriented development model, the government must eliminate the impulse to expand investment and prevent low-level redundant construction. In view of the government function's offside, dislocation and absence, it is necessary to deepen the political system reform, standardize the government behavior, accelerate the transformation of government functions, and actively promote the change of the government's role.

\subsection{To greatly improve the efficiency level of the economic growth and} promote the sustainable development of the economy

Improving efficiency of the economic growth means that the economy gets more output with less input. The input of economic resources and factors of production must take the long term sustainability of the economic growth as the basic premise. In fact, the efficiency of the economic growth and its sustainability are two aspects of the same problem. The low efficiency with the rapid economic growth has restrained the coordination and sustainable development of China's economy, society and ecological environment. The transformation from the traditional economic development model to the new economic development model is essentially the continuous improvement of the economic growth efficiency. It is necessary to improve the use efficiency of various factors of production and the matching efficiency of different factors by virtue of technological innovation and institutional innovation, so as to realize the intensive economic growth. With the development of circular economy, the government can improve the use efficiency of resources and energies to achieve the reduction, re-use and recycle of waste materials in the economic growth, so that China can completely get rid of the traditional economic growth model with high input and high energy consumption.

\subsection{To continuously increase investment in science, technology and education,} and enhance the capability of independent innovation

The improvement of the efficiency level of the economic growth ultimately depends on continuous progress of science and technology. In order to narrow the gap in the overall technological level and the technological level of major industries in the national economy between China and developed countries, the government must continuously increase investment in science, technology and education, and improve the science, technology and education system. In order to achieve long-term development of economy and society, China should focus on the promotion of independent innovation capability with introduction, digestion and absorption of foreign advanced technology. The government should speed up 
the cultivation of innovative talents with various means and strive to bring in a number of key technologies with independent intellectual property rights in the key technological fields and cutting-edge core technology field so that the independent technological innovation will keep pace with the trend of scientific and technological innovation in the world. At the same time, the government should put the industrialization of science and technology on a prominent position in the economic development and technological development. By integrating production, education and research closely and by supporting and taking enterprises as the subject in scientific research, development investment and technological innovation, China can accelerate the pace of the industrialization of scientific and technological innovation .

\section{References}

[1] Li Fuzhu, Zhao Changlin. A Study on the Transformation and Operating Ways of China's Economic Development Model. China Population, Resources and Environment, (02), pp.152-162, 2016.

[2] Ren Baoping, Guo Han. A Study on the Innovation-driven Mechanism of the Transformation of the Economic Development Model. Academic Research, (02), pp.69-75, 2013.

[3] Wu Shi'an. An Analysis of Institutional Barriers in the Transformation of the Economic Development Model. Enterprise Economy, (02), pp.5-13, 2012.

[4] Zhang Guanghui. A Discussion on the Logical Connotation of the Transformation of the Economic Development Model. Modern Economic Research, (08), pp.18-22, 2011.

[5] Kong Xiangmin. A Study on the lack of Driving Force and Countermeasures in the Transformation of China's Economic Development Model. Journal of Beijing Administrative College, (06), pp.66-70, 2010.

[6] Ma Qiangwen, Ren Baoping. A Study on the Performance Evaluation and Influence Factors in the Transformation of China's Economic Development Model. Economist, (11), pp.58-65, 2010.

[7] Wang Keda. A Study on the Institutional Arrangement in Realizing the Transformation of Economic Development Model. Journal of Jiangxi University of Finance and Economics, (03), pp.5-10, 2010. 